\title{
A "CASA COMUM": \\ POR UMA EPISTEMOLOGIA DO CUIDADO E DA JUSTIÇA PARA A AMÉRICA LATINA
}

\author{
Sérgio Ricardo Fernandes de Aquino \\ Doutor e Mestre em Direito pela Universidade do Vale do Itajaí (UNIVALI). \\ Professor do Programa de Pós-Graduação stricto sensu em \\ Direito da Faculdade Meridional (IMED). \\ E-mail: sergiorfaquino@gmail.com \\ Neuro José Zambam \\ Doutor em Filosofia pela Pontifícia Universidade Católica do Rio Grande do Sul (PUCRS). \\ Mestre em Sistemas Éticos pela Universidade do Vale do Rio dos Sinos (UNISINOS) \\ Professor Permanente do Programa de Pós-Graduação stricto sensu \\ em Direito da Faculdade Meridional (IMED). \\ E-mail: neurojose@hotmail.com
}

\section{RESUMO}

A tese que orienta esta investigação é a defesa da existência de uma epistemologia do cuidado e da justiça da "Casa Comum" na Encíclica Laudato Si. Busca-se definir o significado dessa metáfora e defende-se que seu conteúdo pode orientar a construção de soluções sustentáveis para os graves problemas da América Latina, especificamente as desigualdades sociais, as deficiências da democracia, a exclusão de culturas, o esvaziamento das instituições e o uso incorreto dos recursos ambientais e naturais. $\mathrm{O}$ objetivo geral deste estudo é determinar como a "Casa Comum" se torna o vetor epistêmico de cuidado, de uma nova concepção para a convivência fundamentada na centralidade da vida qualificada como digna ao Homem e Natureza na América Latina. O método de investigação utilizado foi o dedutivo. Como parte das conclusões, é necessário o reconhecimento e o aperfeiçoamento da "Casa Comum" dos latino-americanos para perpetuar o Viver Bem entre todos os seres a partir de responsabilidades que se manifestem de modo sistêmico, cooperativo e integrado.

Palavras-chave: "Casa Comum"; Cuidado; Democracia; Epistemologia; Justiça; Reconhecimento. 


\title{
THE “COMMOM HOME”: FOR AN EPISTEMOLOGY
} OF CARE AND JUSTICE TO LATIN AMERICA

\begin{abstract}
The thesis that guides this research is the defense of an epistemology of care about our 'common home' in the Encyclical Laudato Si. The authors seek to define the meaning of this metaphor and argue that its contents can guide the construction of sustainable solutions to the serious problems in Latin America, specifically, social inequalities, deficiencies of democracy, the exclusion of cultures, the emptyness of the institutions and the incorrect use of environmental and natural resources. The main objective of this study is to inquire how the "common home" becomes the epistemic vector to care actions for a new design of living based on the centrality of qualified life among Man and Nature in Latin America. The approach method was deductive. As part of our conclusions, recognition and development of the "common home" of Latin Americans perpetuates the Commom Good among all beings from responsibilities which manifests in a systemic, cooperative and integrated way.
\end{abstract}

Keywords: Care; Commom Home; Democracy; Epistemology; Justice; Recognition. 


\section{INTRODUÇÃO}

As condições de Justiça Social (PASOLD, 2013, p. 55) e Ecológica (BOSSELMANN, 2015, p. 133) ${ }^{2}$, no cenário das graves ameaças que pairam sobre as relações entre os povos, o meio ambiente e as culturas, clamam pela elaboração de novas referências para orientar e estruturar o ambiente de forma solidária e interdependente, evitando as exclusões e outras formas de dominação e exploração. A publicação da Encíclica Laudato $\mathrm{Si}$ - carta de doutrina cristã na qual o papa Francisco realiza críticas ao desinteresse ecológico global sobre as mudanças climáticas, o consumo em demasia, os altos índices de pobreza que impedem o aperfeiçoamento humano e a união dos povos - representa a síntese dessa abordagem sistêmica e universal com as categorias essenciais para abordar temas da atualidade de forma interdisciplinar e cooperativa, tendo em vista o bem de todos.

O Século XXI deverá ser capaz de construir um conjunto de "utopias concretas" (BLOCH, 2005, v.1, p. 145) $)^{3}$, não ilusórias, com capacidade de unir as pessoas e os povos para, conjuntamente, cuidarem da "Casa Comum". Essa é uma dimensão essencial para legitimar toda e qualquer forma de convivência no futuro, seja entre os seres humanos ou desses com a Natureza, no seu sentido mais amplo. A interrogação que orienta essa investigação e parte das pessoas preocupadas com o presente e o futuro sustentáveis é: Como é possível cuidar da "Casa Comum" a fim de que essa atitude se torne a identidade deste século?

\footnotetext{
1 "Quanto à JUSTIÇA SOCIAL, ao aceitar o esquema teórico proposto, é preciso incorporá-la como atitude e, coerentemente, exercê-la em comportamentos. Assim, quando se solicita JUSTIÇA SOCIAL, não se pode realizar o apelo ingênua ou maliciosamente - como se o seu destinatário único fosse o Estado, ou um outro, como o Governo. O verdadeiro destinatário dos apelos à JUSTIÇA SOCIAL é o seu Agente: - o todo social, ou seja, a Sociedade. A JUSTIÇA SOCIAL somente apresentará condições de realização eficiente, eficaz e efetiva se a Sociedade, no seu conjunto, estiver disposta ao preciso e precioso mister de contribuir para que cada pessoa receba o que lhe é devido pela sua condição humana. E, da parte do Estado, caso ele exerça uma efetiva, contínua e legítima Função Social. Neste contexto, destaco três pontos estratégicos: $1^{\circ}$ - a noção de JUSTIÇA SOCIAL não pode ser presa a esquemas fixados a priori e com rigidez indiscutível; $2^{\circ}$ - a conduta do Estado não pode ser paternalista para com os necessitados e protetora ou conivente para com os privilegiados; $3^{\circ}$ - a responsabilidade pela consecução da JUSTIÇA SOCIAL na sua condição de destinação da FUNÇÃO SOCIAL, deve ser partilhada por todos os componentes da Sociedade". As expressões em maiúsculas são originais da obra estudada.

2 “[...] 'Ecológico' pode ser entendido como a modificação de 'justiça' em muito, da mesma forma que 'sustentável pode ser entendido como a modificação de desenvolvimento. Nesta base, os únicos caminhos possíveis para o desenvolvimento são aqueles ecologicamente sustentáveis. Da mesma forma, os únicos caminhos possíveis à justiça são aqueles que reconhecem a sustentabilidade ecológica".

3 "[...] O ponto de contato entre sonho e vida, sem o qual o sonho produz apenas utopia abstrata e a vida, por seu turno, apenas trivialidade, apresenta-se na capacidade utópica colocada sobre os próprios pés, a qual está associada ao possível-real. [...] aqui teria lugar o conceito de utópico-concreto, apenas aparentemente paradoxal, ou seja, um antecipatório que não se confunde com o sonhar utópico abstrato, $[\ldots] "$.
} 
A Encíclica Laudato $S i$, por meio das suas características específicas e de sua tradição, tem caráter universal, como atesta o seu parágrafo inicial: "Nesta Encíclica, pretendo especialmente entrar em diálogo com todos acerca da nossa "Casa Comum"' (FRANCISCO, 2015, p. 10). A tese que o autor apresenta e fundamenta desenvolve reflexões sobre a epistemologia do cuidado da "Casa Comum" como fundamento da atuação humana no mundo, bem como de sua responsabilidade integrada, interdependente e solidária para com os demais, sejam humanos ou não.

Afirma-se, com igual intensidade e objetividade, que essa compreensão é orientada por uma hermenêutica atualizada, que insiste na necessidade de efetivação das condições de justiça para a preservação de uma postura simbiótica, cooperativa entre Homem e Natureza na América Latina.

As dimensões que envolvem as relações humanas, ambientais, democráticas e sustentáveis neste continente estão diretamente associadas às condições em que se encontra a "Casa Comum", isto é, o lugar de todos. Segundo considera Zarka (2014. p. 48),

a apropriação do mundo natural de forma indiscriminada, a instrumentalização do Estado com suas instituições, o processo de exclusão social de culturas, das minorias ou das vítimas de outras formas de violência, preferências e sistemas sociais denunciam a adulteração da "Casa Comum".

Deve-se insistir no argumento: o esclarecimento acerca da expressão "Casa Comum" somente se desenvolve na medida em que o cui-

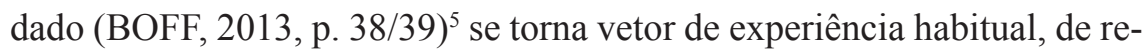
conhecimento sobre a importância do Outro - seja humano ou não-humano

4 "[...] A partir do conceito de inapropriabilidade da Terra, esse direito se amplia consideravelmente: ele comporta não só a hospitalidade, mas também os direitos humanos, o direito à resistência dos povos à opressão política e à superexploração produtivista da Terra e também o direito de gozar os frutos da Terra no lugar onde eles se encontram, bem como o direito a uma vida decente. Esse conjunto definiria a responsabilidade cosmopolita para com a humanidade. Deve, portanto, ser possível inferir da inapropriabilidade da Terra um princípio de solidariedade e justiça universal que, por um lado, sirva como um padrão normativo aos direitos estatais e, por outro lado, baseie a resistência, ainda que em termos puramente morais, aos vários modos de espoliação exercidos por aqueles que se deixam levar pela vertigem da apropriação".

5 "Um modo-de-ser não é um novo ser. É uma maneira do próprio ser de estruturar-se e de dar-se a conhecer. $\mathrm{O}$ cuidado entra na natureza e na constituição do ser humano. O modo-de-ser cuidado revela de maneira concreta como é o ser humano. Sem o cuidado, ele deixa de ser humano. Se não receber cuidado, desde o nascimento até a morte, o ser humano desestrutura-se, definha, perde sentido e morre. $\mathrm{Se}$, ao largo da vida, não fizer com cuidado tudo o que empreender, acabará por prejudicar a si mesmo e por destruir o que estiver à sua volta. Por isso o cuidado deve ser entendido na linha da essência humana (Que responde à pergunta: o que é o ser humano?). O cuidado há de estar presente em tudo". 
- para consolidar projetos para uma vida comum na qual partilhe todas as adversidades a fim de superar esses momentos e incentivar - mais e mais - condições de dignidade a todos. Nenhuma "casa" acolhe a violência, o abandono, a opressão, mas, ao contrário, identifica a fragilidade, conforme Boff $(2009 \text {, p. } 75 / 76)^{6}$, dos seres e os protege. É nesse critério que, aos poucos, a "Casa" se torna mais ampla, "Comum" entre os diferentes habitats da América Latina.

Nesse contexto, podem-se visualizar inúmeras perspectivas e, simultaneamente, iguais possibilidades de reconfiguração da condição humana, da estrutura social e da natureza no presente, bem como as condições de existência no futuro. Essa é a abordagem e a preocupação deste texto. A reversão desse cenário, se orientada pelo pensamento contido no documento papal, contempla todos os atores sociais e reivindica suas "responsabilidades comuns"7 (ZARKA, 2014, p. 46) para estreitar os laços de convivência entre todas as formas de manifestação vital deste continente.

A metáfora de Francisco utilizada na Encíclica Laudato Si (2015, p. 9) - o cuidado da "Casa Comum" - precisa ser entendida a partir de seu significado simbólico e do conjunto de suas orientações. Essa é a base a partir da qual se pode originar uma reconfiguração da realidade, alternativa ao atual corpo de doutrinas de matriz utilitarista, que associa interesses perversos à liberdade e reduz a política, a economia e a cultura aos parâmetros do mercado excludente, submetendo, especialmente, a concepção de justiça e o ordenamento jurídico ao individualismo moral.

Por epistemologia entende-se a investigação analítica dos fundamentos básicos que sustentam e justificam uma concepção ou conviç̧ão - seja de mundo, seja de uma área específica. De forma sistemática, constitui o núcleo de referências de como é possível propor uma arquitetura de conhecimento que expõe determinado tema teórico ou desenvolve argumentos em favor de soluções para problemas normalmente complexos e

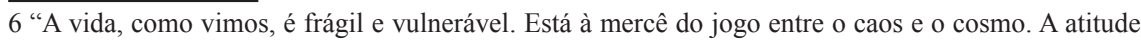
adequada para a vida é o cuidado, o respeito, a veneração e a ternura. [...] São essas atitudes que nos abrem à sensibilização da importância da vida. Elas implicam a mudança do paradigma cultural vigente, assentado sobre poder-dominação, e a introdução de um paradigma de convivência cooperativa, de sinergia, de enternecimento por tudo o que existe e vive. Em razão dessa viragem, urge redefinir os fins inspirados na vida e adequar os meios para esses fins. Só assim a vida ameaçada terá chance de salva-guarda e promoção".

7 “[...] A responsabilidade para com a humanidade também pressupõe um vínculo, mas um vínculo cosmopolita, desta vez, portanto, universal. Trata-se, certamente, de uma responsabilidade comum, que é imposta aos indivíduos e às coletividades, devido ao vínculo pré-originário, porque nos faz quem somos. Esse vínculo pré-originário é a pertença à Terra antes de qualquer percepção, de qualquer pensamento e da ação. Ora, essa pertença significa que não é a Terra que nos pertence, mas que nós pertencemos a ela: trata-se de algo que se encontra em um nível acima de qualquer apropriação; em suma, é inapropriável". 
que demandam conjugação de interesses diversificados e atores com multiplicidade de concepções sobre a vida, o mundo e as pessoas.

Nessa linha de pensamento, o objetivo geral deste artigo é investigar como a "Casa Comum" se torna o vetor epistêmico de cuidado, de uma nova concepção para a convivência fundamentada na centralidade da vida qualificada como digna ao Homem e à Natureza na América Latina. Para desenvolver essa finalidade, escolheram-se como objetivos específicos: a) reconhecer a importância de todas as vidas que habitam a "Casa Comum"; b) identificar a necessidade do cuidado como fundamento de desenvolvimento e de esclarecimento da "Casa Comum"; c) propor a necessidade de uma postura epistêmica acerca desse vetor de convivência para a contínua manutenção e aperfeiçoamento da "Casa Comum".

Este estudo assenta-se sobre três áreas: na primeira, aborda-se o "cuidado da "Casa Comum" como núcleo estruturante das referências. Na segunda, o cuidado da América Latina, que elege a necessidade de atualizar e de contextualizar o conteúdo central da justiça num ambiente complexo e exigente. Na terceira, a concepção de Homem e de sua responsabilidade sistêmica e solidária com todos os seres que habitam igual tempo e espaço.

O método que orienta esta investigação é o dedutivo (PASOLD, 2015, p. 205) ${ }^{8}$ porque a Encíclica Laudato Si, como a referência mais importante e por seu caráter, torna-se o núcleo a partir do qual se busca avaliar e justificar as possíveis soluções para a América Latina, em suas múltiplas exigências e conjuntura, e também esclarecer a concepção e a responsabilidade humana não dominada pelo tecnicismo ou pelo antropocentrismo radical.

Associam-se aos estudos propostos os esforços deste artigo como pesquisa exploratória. Já as técnicas empreendidas aparecem pelo uso da pesquisa bibliográfica e documental (PASOLD, 2015, p. 207) ${ }^{9}$, da categoria (PASOLD, 2015, p. 25) $)^{10}$ e conceito operacional (PASOLD, 2015, p. 37) ${ }^{11}$, quando necessários, na medida em que se buscam referências

8 "[...] base lógica da dinâmica da Pesquisa Científica que consiste em estabelecer uma formulação geral e, em seguida, buscar as partes do fenômeno de modo a sustentar a formulação geral".

9 “[...] Técnica de investigação em livros, repertórios jurisprudenciais e coletâneas legais”.

10 "[...] palavra ou expressão estratégica à elaboração e/ou à expressão de uma idéia". Grifos originais da obra em estudo.

11 "Quando nós estabelecemos ou propomos uma definição para uma palavra ou expressão, com o desejo de que tal definição seja aceita para os efeitos das idéias que expomos, estamos findando um Conceito Operacional [...]". Grifos originais da obra em estudo. 
teóricas, seja para tornar mais clara a compreensão do texto, seja para a contextualização do conteúdo original ou para apresentar o domínio dos conceitos, com vistas a esclarecer determinados fenômenos.

\section{LAUDATO SI E O CUIDADO DA "CASA COMUM"}

O cuidado do meio ambiente (FRANCISCO, 2015, p. 86) ${ }^{12}$, das pessoas, da equidade social e das futuras gerações é um compromisso fundamental para preservar condições mínimas de sobrevivência humana e do mundo natural. Nesse caso, o mencionado autor (2015, p. 9), de forma corajosa, inicia seu escrito denunciando os abusos cometidos pelo Homem sobre a Terra, a "Casa Comum": "Esta irmã clama contra o mal que the provocamos por causa do uso irresponsável e do abuso dos bens que Deus nela colocou. Crescemos pensando que éramos seus proprietários e dominadores, autorizados a saqueá-la".

A compreensão dessa afirmação é fundamental para descobrir, afirmar e orientar a construção de uma epistemologia da "Casa Comum" porque assevera a origem de grande parte dos problemas encontrados nessa área, quais sejam, um antropocentrismo absoluto que elegeu o Homem com poderes de apropriação ilimitada dos recursos disponíveis para satisfazer seus objetivos e interesses. Para viabilizar esse projeto, utilizaramse instrumentos, técnicas, estratégias e invenções cada vez mais potentes, sofisticadas e eficientes, sem qualquer apreço pela finitude da Natureza.

Nota-se que, no decorrer do escrito, há uma observação que denuncia uma hermenêutica limitada em relação à compreensão da obra da criação e da identidade do Homem, segundo Francisco (2015, p. 45-47) ${ }^{13}$. O esclarecimento sobre a vitalidade da "Casa Comum" sugere, ao contrá-

12 “Quando falamos de 'meio ambiente', fazemos referência também a uma particular relação: a relação entre natureza e a sociedade que a habita. Isto impede-nos de considerar a natureza como algo separado de nós ou como uma mera moldura da nossa vida. Estamos incluídos nela, somos parte dela e compenetramo-nos. As razões pelas quais um lugar se contamina exigem uma análise do funcionamento da sociedade, de sua economia, de seu comportamento, de suas maneiras de entender a realidade. Dada a amplitude das mudanças, já não é possível encontrar uma resposta específica e independente para cada parte do problema. É fundamental buscar soluções integrais que considerem as interações dos sistemas naturais entre si e com os sistemas sociais. Não há duas crises separadas: uma ambiental e outra social; mas uma única e complexa crise socioambiental. As diretrizes para a solução requerem uma abordagem integral para combater a pobreza, devolver a dignidade aos excluídos e, simultaneamente, cuidar da natureza".

13 A compreensão de Francisco observa os limites da hermenêutica dos textos bíblicos, especialmente quando se refere à disposição dos bens da natureza e da própria missão do homem que, segundo afirma, conduz a um antropocentrismo despótico. O contrário, conduz a uma ética do cuidado e da responsabilidade com a natureza, o homem e os demais. A compreensão errônea de domínio desconsiderando o seu sentido original e sua repercussão em diferentes contextos deturpou o sentido da ação humana e o próprio sentido da natureza. 
rio, uma hermenêutica integral e sistêmica para reconhecer e experimentar quais atitudes não respeitam os limites do próprio humano e do meio natural, com o objetivo de instaurar, no decorrer do tempo, uma genuína comunhão universal (FRANCISCO, 2015, p. 58) ${ }^{14}$.

O cuidado da "Casa Comum", conforme o entendimento desse autor, compreende uma ação do Homem pautada pelo reconhecimento de sua grandeza e pela consciência da responsabilidade solidária e cooperativa em relação aos demais homens e - de forma ampliada, com igual sensibilidade - aos demais seres vivos (REIS; BIZAWU, 2015, p. 50) ${ }^{15}$. A "Casa Comum" é a casa de todos os seres - humanos e não-humanos; logo, a consciência do cuidado, associada atualmente, com a percepção de que os recursos naturais e ambientais são finitos, aguça com maior intensidade a prerrogativa da responsabilidade comum.

Cuidado - insiste-se - não significa apenas olhar para si e reconhecer os limites de uma condição e de natureza humana, porém, da mesma forma, significa sentir, ser cúmplice das angústias, da opressão, da miséria causada aos seres vivos, que não se comunicam sob o mesmo critério linguístico e racional humano. É necessário, sim, desenvolver uma sensibilidade aguçada para ouvir os clamores silenciosos da Terra. Cuidado é atitude desinteressada de acolhimento generoso ao Outro. Cuidado, para o pontífice (2015, p. 59), é expressão de um valor jurídico e democrático na medida em que favorece a proximidade entre os seres e o seu desenvolvimento interespécies ${ }^{16}$.

O não cuidado da "Casa Comum" evidencia a existência de injustiças que precisam ser sanadas. Nessa dinâmica, Francisco (2015, p. 50) afirma, com igual convicção e serenidade: "Por isso, a injustiça não é invencível". Em torno dessa convicção, a prerrogativa de bem cuidar a

14 "As criaturas deste mundo não podem ser consideradas um bem sem dono [...]. Isto gera a convicção de que nós e todos os seres do universo, sendo criados pelo mesmo Pai, estamos unidos por laços invisíveis e formamos uma espécie de família universal, uma comunhão sublime que nos impele a um respeito sagrado, amoroso, humilde. [...]. Isto não significa igualar todos os seres vivos e tirar ao ser humano aquele seu valor peculiar que, simultaneamente, implica uma tremenda responsabilidade. Também não requer uma divinização da terra, que nos provaria de nossa vocação de colaborar com ela e proteger a sua fragilidade. Essas concepções acabariam por criar novos desequilíbrios, na tentativa de fugir da realidade que nos interpela. [...]. Devemos, certamente, ter a preocupação de que os outros seres vivos não sejam tratados de forma irresponsável, mas deveriam indignar-nos sobretudo as enormes desigualdades que existem entre nós, porque continuamos a tolerar que alguns se consideram mais dignos que outros".

15 "Francisco afirma a necessidade de uma abordagem integral, isto é, que leve em consideração os aspectos naturais e sociais. Há uma interdependência entre os níveis mais elementares (subatômicos e genéticos) até os níveis maiores (ecossistemas)".

16 “[...] Tudo está interligado. Por isso, exige-se uma preocupação pelo meio ambiente, unida ao amor sincero pelos seres humanos e a um compromisso constante com os problemas da sociedade". 
"Casa Comum" é uma realidade possível de ser pensada e efetivada nos diversos ambientes e por inúmeros agentes, sejam com liderança expressiva e reconhecida ou não.

Esse argumento é incisivo: sem o esclarecimento oportunizado pelo cuidado não é possível sequer cogitar a existência de uma "Casa Comum". É a partir do reconhecimento ao "Outro absolutamente Outro" (LÉVINAS, 2000, p. 176) ${ }^{17}$, especialmente no caso da Natureza, que o ego se dilui e se movimenta para Outrem. A projeção e consolidação histórica da "Casa Comum" como espaço da tolerância (ZAMBAM; AQUINO, 2015 , p. 382 $)^{18}$, da diversidade, do acolhimento somente se manifesta pela ação de cuidado diante do Outro sempre precário, provisório, incompleto e finito.

É aqui que a palavra de Francisco $(2015$, p. 9) tem sentido: “[...] a nossa 'Casa Comum' se pode comparar ora a uma boa irmã, com quem partilhamos a existência, ora a uma boa mãe, que nos acolhe nos seus braços [...]”. Eis, portanto, uma pergunta apropriada: Quem é violento contra alguém que o acolhe, sejam humanos ou não humanos?

Nesse ambiente, simultaneamente de perplexidade e esperança, destaca-se: Quem é o Homem? Qual sua missão e identidade social? Qual é a condição dos animais não humanos e da natureza? A convicção de Francisco (2015, p. 54) é esclarecedora: "A partir dos textos bíblicos, consideramos o ser humano como sujeito, que nunca pode ser reduzido à categoria de objeto". Essa referência contempla a mais cara tradição democrática desde a sua origem, que consagra o Homem como sujeito de direitos, prerrogativa largamente contemplada na Constituição da República Federativa do Brasil de 1988.

Semelhante argumento se observa, também, a partir das Constituições do Equador e da Bolívia, nas quais a Natureza se torna sujeito de direitos, protegida não por ser algo meramente útil ou existe somente pelos juízos de valores humanos - estéticos, industriais, econômicos, tec-

17 “[...] o Outro, absolutamente Outro - Outrem - não limita a liberdade do mesmo. Chamando-o à responsabilidade, implanta-a e justifica-a. A relação com o outro enquanto rosto cura da alergia, é desejo, ensinamento recebido e oposição pacífica do discurso".

18 “A afirmação da Tolerância como um valor fundamental para a avaliação da arquitetura, do funcionamento, das garantias de estabilidade social e política, das políticas de desenvolvimento e das relações entre culturas ou concepções diferentes, inúmeras vezes conflitantes, representa a convicção moral e uma conquista histórica com condições de impulsionar os diferentes campos de relacionamento, a organização e o funcionamento das sociedades caracterizadas pelas deficiências e dificuldades para compreender e efetivar o exercício da práxis (sempre mais) tolerante. O valor da Tolerância precisa integrar o que se pode chamar de imaginário social ou, também, a compreensão de razão pública da sociedade democrática. Entretanto, a ausência de um exercício intrassubjetivo sobre o reconhecimento dos limites e deficiências humanas e sociais cria o self deception (autoengano) acerca do que é ser humano e, portanto, incita práticas sempre mais intolerantes". Grifos originais do artigo estudado. 
nológicos, cujos benefícios direcionam-se somente às presentes e futuras gerações -, mas porque é um "ser próprio".

A "Casa Comum" somente tem sentido porque todos usufruem de seus bens comuns (MATTEI, 2013, p. 16/17) ${ }^{19}$, desde o mais vulnerável - inclusive os ecossistemas - até a pessoa com maior concentração de riquezas econômicas. Nenhum ser vivo é objeto de opressão, miséria e exploração para benefício de outro. Por esse motivo, Francisco (2015, p. 54) rememora:

[...] seria errado também pensar que outros seres vivos devam ser considerados meros objetos submetidos ao domínio arbitrário do ser humano. Quando se propõe uma visão da natureza unicamente como objeto de lucro e interesse, isso comporta graves consequências também para a sociedade.

A correção dos dramas sociais e naturais supõe a iniciativa do Homem como protagonista, e não como dominador, da mesma forma que a superação da relação de apropriação dos recursos naturais e ambientais deve, também, atender às possibilidades de outras graves dicotomias: "É evidente a incoerência de quem luta contra o tráfico de animais em risco de extinção, mas fica completamente indiferente perante o tráfico de pessoas, desinteressa-se dos pobres ou procura destruir o outro ser humano quem não gosta" (FRANCISCO, 2015, p. 59).

A "Casa Comum" é o referencial da existência humana junto aos demais seres vivos. Ninguém pode apropriar-se desse "modo-de-ser" exaustivamente, sem qualquer referência moral, da tradição cultural ou dos limites e orientações da legislação. A caracterização "comum" foi também esclarecida a fim de evitar contradições e outras inconsistências: "O meio ambiente é um bem coletivo, patrimônio de toda a humanidade e responsabilidade de todos" (FRANCISCO, 2015, p. 61).

A autêntica epistemologia do cuidado da "Casa Comum", morada de todos, implica, conforme destaca Francisco, uma correta compreensão do Homem no exercício de sua autonomia e dotado de talentos, bem como de limitações, que demandam uma persistente atitude habitual de

19 “[...] O tema dos bens comuns, de fato, tem a ver com a questão fundamental sobre o domínio das coisas e da relação da pessoa com a natureza. Por esse motivo, o tema não pode ser abordado, nem compreendido, sem expor no cerne do debate a dimensão institucional do poder e a sua legitimidade. [...] Pensar sobre os bens comuns exige, antes de tudo, uma postura central tipicamente global capaz de situar no centro do problema o problema do acesso igualitário das possibilidades que o planeta nos oferece. Uma perspectiva desse sentido suscita perguntas difíceis de contestar para quem opera numa fé inabalável sobre a constante depredação dos recursos naturais [...]". Tradução livre do original em espanhol dos autores deste texto. 
reconhecimento acerca da complexidade desta rede de vida interespécies. Nesse sentido, sublinha o autor (2015, p. 74) com simplicidade e desejo de transformações profundas: "Mas a interpretação correta do conceito de ser humano como senhor do universo é entendê-lo no sentido de administrador responsável”.

Talvez a partir dessas palavras seja necessário, ao estilo do pensamento de Kant, propor neste artigo um imperativo categórico, a fim de orientar a ação humana para rasgar o véu que impede esse estar-junto-como-Outro-no-mundo: "Cuida de si para reconheceres a fragilidade da vida e disseminar, por meio das suas decisões, atitudes que preservem o Outro na sua absoluta diferença".

A associação da "Casa Comum" com a responsabilidade moral na afirmação da relação interdependente e complementar entre todos os seres vivos clama pelo reconhecimento do imperativo da responsabilidade (GIACOIA JÚNIOR, 2000, p. 199) ${ }^{20}$ para insistir, no cotidiano, na repercussão do distanciamento do Homem, da Natureza, da mentalidade exclusivamente técnica (GIACOIA JÚNIOR, 2000, p. 200)21 diante das prerrogativas morais. O cuidado da "Casa Comum" precisa integrar o agir individual e coletivo.

\section{LAUDATO SI: CUIDADO E JUSTIÇA PARA A AMÉRICA LATI- NA}

A "Casa Comum" dos latino-americanos tem contornos específicos, considerando a sua formação cultural, as riquezas naturais e ambientais, a expressiva presença de indígenas, a trágica experiência da escravidão associada ao massacre de outros povos, as desigualdades econômicas e a persistente instabilidade política.

Nesse contexto, as persistentes desigualdades ameaçam o equilíbrio social e a diversidade cultural e ambiental. Faz-se necessária a educação para os valores caros da tradição democrática, com destaque para a tolerância, a justiça, a solidariedade, a superação de preconceitos e as

20 Considerando o niilismo contemporâneo evidenciado, Hans Jonas propôs um indicativo para o agir moral na época de domínio do saber técnico: "Age de maneira tal que os efeitos da tua ação sejam compatíveis com a permanência de autêntica vida humana sobre a terra".

21 Giacoia Júnior explica como a proposição de Hans Jonas não pode ser reduzida ao individualismo moral ou a práticas restritas de corporações ou a ações de grupos isolados: "O novo imperativo ético não se dirige [...] ao comportamento do indivíduo privado, mas ao agir coletivo, sua destinação não é, portanto, à esfera próxima das relações entre singulares, mas a do domínio da esfera pública. Jonas reivindica uma nova espécie de concordância: não a incompatibilidade interna da vontade, nem aquela do ato consigo mesmo, mas a concordância entre os efeitos últimos do ato com a permanência de atividade humana autêntica no futuro". 
outras formas de classificação de pessoas, além da construção de outros paradigmas de relacionamento com a Natureza. O pensamento de Francisco orienta essa proposição de um paradigma da sustentabilidade de matriz ecológica (BOSSELMANN, 2015, p. 50-56).

Os povos latino-americanos precisam conjugar esforços para que o cuidado da "Casa Comum" represente o justo objetivo que impulsiona e une os diversificados atores - humanos ou não - em torno de metas comuns em vista das condições de vida humana e ambientais equitativas. Nesse esforço, Francisco destaca especial emoção e preocupação com a Amazônia, como um dos pulmões do planeta que necessita ser cuidado com especial responsabilidade, o que pode ser feito especialmente a partir da cidadania expressa por Gudynas (2009, p. 66) como "Florestania"22

A sensibilidade do escrito reconhece os inúmeros esforços de parte significativa da população e das organizações sociais para mitigar a intensidade das misérias humanas. Com igual ênfase e preocupação, são denunciados os interesses internacionais que expropriam os seus recursos da Amazônia movidos apenas pela lógica de mercado e dos interesses econômicos de diferentes líderes e instituições.

Essa é uma prerrogativa, segundo o relato de Francisco, fundamental para congregar os povos em vista do cuidado e justiça para a "Casa Comum" latino-americana (2015, p. 29). Precisa-se, de início, pensar uma política internacional, num projeto comum (2015, p. 99/100) ${ }^{23}$, para empreender essas ações, seja na dimensão continental e, após, na dimensão mundial. Citam-se como exemplo os esforços feitos pela União de Nações Sul-Americanas - UNASUL (2016) - no artigo segundo de seu Tratado Constitutivo ${ }^{24}$.

22 "[...] Ideas como la de florestanía permiten incorporar una perspectiva biocéntrica, aunque el caso actual más destacado es la ya mencionada nueva constitución ecuatoriana, donde se reconocen derechos propios en la Naturaleza, la que incluso aparece bajo la concepción alterna de Pachamama [...]. En el caso ecuatoriano coexistirían una ciudadanía ambiental junto a elementos para una nueva meta-ciudadanía ecológica. La postura biocéntrica también sirve como fuente de obligaciones y responsabilidades, tanto frente al resto de la sociedad, como también ante la Naturaleza, y desde alli abordar nuevas estrategias de justicia ambiental".

23 “[...] a mesma inteligência que foi utilizada para um enorme desenvolvimento tecnológico não consegue encontrar formas eficazes de gestão internacional para resolver as graves dificuldades ambientais e sociais. Para enfrentar os problemas de fundo, que não se podem resolver com ações de países isolados, torna-se indispensável um consenso mundial que leve, por exemplo, a programar uma agricultura sustentável e diversificada, a desenvolver formas de energia renováveis e pouco poluidoras, a fomentar uma maior eficiência energética, a promover uma gestão mais adequada dos recursos florestais e marinhos, a garantir a todos o acesso à água potável".

24 "A União de Nações Sul-Americanas tem como objetivo construir, de maneira participativa e consensuada, um espaço de integração e união no âmbito cultural, social, econômico e político entre seus povos, priorizando o diálogo político, as políticas sociais, a educação, a energia, a infraestrutura, o financiamento e o meio ambiente, entre outros, com vistas a eliminar a desigualdade socioeconômica, 
Uma proposta para o cuidado da "Casa Comum" latino-americana, ancorada na epistemologia da Encíclica Laudado Si, está associada à tradição de vivir bien (HUANACUNI MAMANI, 2010, p. 32). Essa é uma concepção que, além de unir metas, sujeitos e interesses diferentes, situa-se além do modelo em curso, denunciado por Francisco no conjunto da sua exposição, e visa a outra forma de viver, conforme assinala o autor (2010, p. 3):

O paradigma comunitário da cultura da vida para viver bem, sustentado por uma forma de vida refletida numa prática cotidiana de respeito, harmonia e equilíbrio comunitário com tudo o que existe, compreendendo que na vida tudo está interconectado, é interdependente e está inter-relacionado ${ }^{25}$.

As inúmeras consequências da falta de cuidado, da omissão e da exploração do mundo natural na "Casa Comum" dos latino-americanos intensificam as profundas - e históricas - desigualdades neste continente. A compreensão de uma forma de viver integrada, justa, respeitosa e solidária precisa compreender a necessária responsabilidade comum que supere a visão limitada e dependente da ação humana. No entanto, observa-se também como o atual modelo de desenvolvimento é o primeiro responsável pela situação caótica em que se encontra o meio ambiente comum, como esclarece Francisco (2015, p. 31):

Tendo em conta que o homem também é criatura deste mundo, que tem direito a viver e ser feliz e, além disso, possui uma dignidade especial, não podemos deixar de considerar os efeitos da degradação ambiental, do modelo atual de desenvolvimento e da cultura do descarte sobre a vida das pessoas.

Pode-se destacar nessa afirmação, a partir da proposição citada, a visão de Homem situado numa relação de igualdade equitativa com os demais seres da natureza e com responsabilidade moral para com todos. Uma concepção antropológica atualizada inviabiliza a ação do Homem como senhor absoluto sobre a Natureza e os demais seres. Não é possível, segundo Bosselmann (2015, p. 129) elaborar caminhos para uma vida mais sustentável sem que a Justiça não seja compreendida, também, sob o viés

alcançar a inclusão social e a participação cidadã, fortalecer a democracia e reduzir as assimetrias no marco do fortalecimento da soberania e independência dos Estados".

25 Tradução livre dos autores deste texto do original em espanhol. 
ecológico ${ }^{26}$.

As dificuldades de formalizar e, posteriormente, de efetivar acordos em nível global impactam também a América Latina devido a interesses majoritariamente corporativos e dominados pela voracidade do mercado ou, sob outro ângulo, pelas ideologias políticas dominantes desde períodos distantes, que se perpetuam em muitos países (GUARDINI, 2000 , p. 55) ${ }^{27}$. Essas deficiências quando avaliadas, segundo a orientação do cuidado da "Casa Comum", demonstram a necessidade de uma nova forma de viver construída pela participação e pelo empenho de todos.

Novamente, insiste-se: a ausência habitual do cuidado ou da sustentabilidade não favorecem qualquer estímulo ou esclarecimento acerca da "Casa Comum" dos latino-americanos, mas, ao contrário, isola as nações que, cegas por seus interesses, não sabem como lidar com dificuldades transversais, comuns, que impedem um desenvolvimento mais qualitativo a todos. Por esse motivo, Francisco (2015, p. 121) reitera: "Sempre é possível desenvolver uma nova capacidade de sair de si mesmo rumo ao outro. Sem essa capacidade não se reconhece às outras criaturas o seu valor, não se sente interesse em cuidar de algo para os outros [...]".

Essa visão foi atualizada, ainda, por Huanacuni Mamani (2010, p. 68): "viver melhor é consequência de um modelo não apenas econômico, mas maior, um modelo espiritual. Portanto, para se chegar ao horizonte do bem viver, não se pode repensar apenas a estrutura e o modelo econômico, mas precisa-se reconstruir a cosmovisão da cultura ${ }^{28}$ ".

A descrição desse cenário torna-se mais explícita e coerente com os dilemas da América Latina quando Francisco esclarece as consequências sociais dessa falta de cuidado dos recursos naturais e ambientais disponíveis e, ainda, abundantes. O Pontífice (2015, p. 33) cita, de forma esclarecedora, a opinião da Igreja Católica boliviana:

De fato, a deterioração do meio ambiente e da sociedade afetam de modo especial os mais frágeis do planeta: 'tanto a experiência comum da vida cotidiana como a

\footnotetext{
26 “A proximidade do ecocentrismo com a sustentabilidade ecológica é o caminho mais promissor para uma teoria funcional da justiça ecológica. [...] Para se tornar um conceito verdadeiramente ecológico, a justiça precisa chegar ao mundo não humano. [...] Não é o suficiente cuidar dos seres humanos que vivem hoje e amanhã, quando os processos naturais que sustentam a vida estão em risco. Há uma necessidade de identificar e reconhecer a importância ética e jurídica da integridade ecológica".

27 “[...] os homens serão cada vez mais naturalmente considerados objetos, desde as modas incontáveis de captação, pela administração e pela estatística até as inimagináveis violações do indivíduo, dos grupos e até dos povos. E isto não apenas nas necessidades e paroxismos da guerra, mas como forma normal de governo e administração".
}

28 Tradução livre do original em espanhol dos autores deste texto. 
investigação científica demonstram que os efeitos mais graves de todas as agressões ambienteis recaem sobre as pessoas mais pobres'.

A partir desse argumento, outra afirmação de Francisco (2015, p. 132) - "O amor, cheio de pequenos gestos de cuidado mútuo, é também civil e político, manifestando-se em todas as ações que procuram construir um mundo melhor" - enfatiza o alcance e a capacidade dos seres humanos para transformar realidades complexas como as da América Latina. Sob igual critério, fomenta-se a reconstrução do sentido da atuação política daqueles sob os quais está a responsabilidade moral e jurídica em vista de uma forma adequada e responsável de cuidar da casa de todos.

\section{LAUDATO SI: A RESPONSABILIDADE PELA "CASA COMUM" DOS LATINO-AMERICANOS}

O compromisso do continente latino-americano em vista do cuidado da casa de todos, segundo o princípio da responsabilidade descrito por Giacoia Júnior (2000, p. 194), é sublinhado como: “[...] a ideia de dever e responsabilidade do agente humano relativamente à natureza e ao futuro das próximas gerações humanas sobre a terra". Ao considerar que a responsabilidade primeira é do Homem, este é chamado a uma atuação efetiva, conforme sua identidade e missão. Nas palavras de Francisco (2015, p. 79),

Somos chamados ao trabalho desde a nossa criação. Não se deve procurar que o progresso tecnológico substitua cada vez mais o trabalho humano: procedendo assim, a humanidade prejudicar-se-ia a si mesma. O trabalho é uma necessidade, faz parte do sentido da vida nesta terra, é caminho de maturação, desenvolvimento humano e realização pessoal.

Essa abordagem precisa conceber o Homem inserido na rede da vida, no conjunto das suas relações e capacidades, para evitar que sua atuação repita o modelo em curso (HUANACUNI MAMANI, 2010, p. 6) ${ }^{29}$, que conduz a um antropocentrismo (SARLET, 2011, p. 42/43) ) $^{30}$ isolado e

29 "[...] os paradigmas de vida dominantes compreendem o indivíduo como o único sujeito de direitos e obrigações, instituindo-o como o único referencial de vida. Portanto, os sistemas jurídico, educativo, político, econômico e social se adequaram e respondem aos direitos e obrigações individuais". Tradução livre do original em espanhol dos autores deste texto.

30 "É justamente no pensamento de Kant que a doutrina jurídica mais expressiva - [...] - ainda hoje parece estar identificando as bases de uma fundamentação e, de certa forma, de uma conceituação de dignidade da pessoa humana. Até que ponto, contudo, tal concepção efetivamente poderá ser adotada sem reservas ou ajustes na atual quadra da evolução social, econômica e jurídica constitui, sem dúvida, desafio fascinante [...]. Assim, poder-se-á afirmar [...] que tanto o pensamento de Kant quanto todas 
autoritário ou, por vezes, a uma ilusão de igualdade entre todos os seres vivos. A percepção da responsabilidade moral precisa compor a educação para o cuidado preventivo, quando se podem antever ações que conduzam ao desequilíbrio entre os ecossistemas, aos conflitos sociais violentos ou a outras formas de destruição e corrupção.

Os recursos e pesquisas disponíveis, associados a legislações atualizadas, são instrumentos legítimos e eficazes para que esses objetivos não sejam esquecidos ou marginalizados pelos interesses nacionais. A busca por uma responsabilidade comum, pelo cuidado comum é o que favorece o esclarecimento de "Casa Comum". Temas como sustentabilidade, por exemplo, são vetores fundamentais para a consolidação histórica da morada terrena, porém nenhum esforço isolado por parte dos Estados-nação é capaz de trazer respostas satisfatórias às dificuldades experimentadas, seja num continente ou no globo. Cuidado, responsabilidade e sustentabilidade reivindicam esforços transnacionais (STAFFEN, 2015, p. 22/23) . $^{31}$.

As deficiências políticas amplamente investigadas na América Latina retratam esse contexto necessitado de esclarecimento moral, de estruturas jurídicas atualizadas e de propostas políticas que preservem o patrimônio natural e cultural das sociedades, contribuam para a participação da sociedade e integrem os povos em vista de metas comuns e contribuam para o bem viver no mundo. A responsabilidade local não pode estar dissociada de compromissos de alcance universal (BOFF, 2012, p. 69);32 ao contrário, deve

as concepções que sustentam ser a dignidade atributo exclusivo da pessoa humana - encontram-se, ao menos em tese, sujeitas à crítica de um excessivo antropocentrismo, notadamente naquilo em que sustentam que a pessoa humana, em função de sua racionalidade [...] ocupa um lugar privilegiado em relação aos demais seres vivos. Para além disso, sempre haverá como sustentar a dignidade da própria vida de um modo geral, ainda mais numa época em que o reconhecimento da proteção do meio ambiente como valor fundamental indicia que não está em causa apenas a vida humana, mas a preservação de todos os recursos naturais, incluindo todas as formas de vida existentes no planeta, ainda que se possa argumentar que tal proteção da vida em geral constitua, em última análise, exigência da vida humana e de uma vida humana com dignidade, tudo a apontar para o reconhecimento do que se poderia designar de uma dimensão ecológica ou ambiental da dignidade da pessoa humana".

31 Para organizar e exercitar esses critérios num cenário transnacional, cogita-se um Direito Global: "[...] o declínio do Estado Constitucional nacional e a ascensão de um paradigma global de Direito decorre, substancialmente, da penetração de critérios de governança nos assuntos e políticas públicas do Estado, logisticamente apoiado pelos avanços tecnológicos. [...] o Direito Global, por mais incipiente que seja, tem como objeto a compreensão e regulação das relações provenientes dos fluxos globalizatórios. Fluxos estes que não se restringem à globalização do segundo pós-guerra".

32 Destaca-se a posição de Boff sobre essa dimensão a fim de evitar o desenvolvimento de novas formas de individualismo social, assim como para perceber a conexão existente na natureza cujas rotas de relacionamento se complementam, corrigem e contribuem para o seu vigor e aprimoramento: "Para realizar estas aspirações devemos decidir viver com um sentido de responsabilidade universal, identificando-nos com toda a comunidade terrestre, bem como com nossa comunidade local. Somos, ao mesmo tempo, cidadãos de nações diferentes e de um mundo no qual as dimensões locais e globais estão ligadas. Uma comparte responsabilidade pelo presente e pelo futuro, pelo bem-estar da família humana e do grande mundo dos seres vivos. O espírito de solidariedade humana e de parentesco com 
estimular o aperfeiçoamento dessa convivência entre todos os seres na Terra.

$\mathrm{Na}$ América Latina, podem-se citar acordos - como é o caso da UNASUL - e legislações ${ }^{33}$ que são indicativos de compromisso social para uma vida sustentável (BOFF, 2013, p. 128) ${ }^{34}$ dos Estados e de instituições (FRANCISCO, 2015, p. 38) (5) $^{35}$ que refletem o compromisso com o cuidado da "Casa Comum" de todos os povos.

Destacam-se também inúmeras pesquisas (KUJAWA, 2015, por exemplo), $\operatorname{congressos}^{36}$, seminários ${ }^{37}$, $\operatorname{conferências~}^{38}$ e outros $^{39}$, que expressam a necessidade de abordagens atualizadas sobre os temas em evidência nessa investigação.

A riqueza do conteúdo desse conjunto de referências terá legitimidade na medida em que contribuírem para a construção de políticas alternativas de relacionamento com os recursos naturais e ambientais, assim como para o aprimoramento da democracia, do exercício dos direitos, da preservação do patrimônio cultural e da diminuição das desigualdades sociais.

A inoperância ou fraqueza das ações tanto em nível local como internacional implode as relações humanas, sociais e ambientais, conforme destaca Francisco (2015, p. 37): "Essas situações provocam os gemidos da irmã Terra, que se unem aos gemidos dos abandonados do mundo, com um lamento que reclama de nós outro rumo. Nunca maltratamos e ferimos nossa 'Casa Comum' como nos últimos dois séculos”.

Essa é uma metáfora que, quando associada aos dilemas da "Casa Comum" dos latino-americanos, retrata as dificuldades e deficiências exis-

toda a vida é fortalecido quando vivemos com reverência o mistério da existência, com gratidão pelo presente da vida e com humildade, considerando o lugar que ocupa o ser humano na natureza".

33 Cita-se como exemplo a Lei n. 12.651, de 25 de maio de 2012, denominada Código Florestal Brasileiro.

34 "Uma sociedade é sustentável quando se organiza e se comporta de tal forma que ela, através das gerações, consegue garantir a vida dos seus cidadãos e dos ecossistemas nos quais está inserida, junto com a comunidade de vida. Quanto mais uma sociedade se funda sobre recursos renováveis e recicláveis, mais sustentável se torna".

35 A posição da Igreja Católica Latino-Americana é uma referência para esse tema: “[...] nas intervenções sobre os recursos naturais, não predominem os interesses de grupos econômicos que arrasam irracionalmente as fontes da vida".

36 IV Congreso de Cultura y Educación para la integración de América Latina - "el Buen Vivir". Democracia, participação e multiculturalismo na América Latina. Ozorno, Chile. Evento realizado no ano de 2015.

37 III Seminário Internacional de Direitos Humanos e Democracia: cidadania, justiça e cidadania. Ijui, RS, Brasil. Evento realizado no ano de 2015.

38 Conferência das Nações Unidas sobre Desenvolvimento Sustentável - a Rio+20. Rio de Janeiro, Brasil. Evento que se realiza de dez em dez anos.

39 Seminário Internacional "Direito, Democracia e Sustentabilidade". Passo Fundo, Brasil. Evento anual que se realiza no mês de agosto. 
tentes no continente que clamam por uma nova forma de organização e cuidado com os bens de todos. A insistência de uma história fundada na opressão e na exploração desmedida - seja de humanos ou do mundo natural - não deve servir como obstáculo aos desejos, às utopias carregadas de esperança de uma integração vital capaz de modificar as falsas promessas travestidas de "progresso" ou de "desenvolvimento sustentável".

A percepção dos limites e ameaças precisam penetrar o imaginário e a atuação dos líderes, das autoridades, das associações e dos cidadãos em geral. Metas comuns fomentam posturas coletivas relevantes e de forte repercussão. Essas atitudes ampliam, mais e mais, a importância dos espaços democráticos, projetando-os como fenômeno transnacional. Uma concepção que conjuga realização humana e compromisso coletivo é sinalizado por Huanacuni Mamani (2010, p. 35):

[...] Tudo vive, e tudo é muito importante para o equilíbrio e a harmonia da vida, o desaparecimento ou a destruição de uma espécie é a destruição da vida. Concebemos que somos filhos da Mãe Terra e do cosmos. Portanto, todas as formas de relação [...] devem estar em permanente equilíbrio e harmonia com o todo, pois, quando se rompem, as consequências são para todos ${ }^{40}$.

O cuidado da "Casa Comum", conforme propõe Francisco, demonstra a necessidade de estruturação de políticas de desenvolvimento sustentável ancoradas em parâmetros alternativos, que contemplem uma nova visão de homem, da natureza e de sociedade sistêmica, cooperativa, solidária e interdependente. A tradicional relação sujeito-objeto é unilateral e supõe a submissão do "Outro" diante do "Eu". Ao invés desse modelo perverso, propõe-se o cuidado da "Casa Comum" como dever moral e compromisso social com as condições de bem viver no presente e para as gerações futuras. Eis as genuínas "utopias concretas", que carregam "esperanças sensatas" (ROSSI, 2013, p. 85) ${ }^{41}$ entre todas as gerações, na manutenção da vida de todos os seres.

\section{CONCLUSÕES}

O cuidado da "Casa Comum" como uma responsabilidade de todos é imperativo moral para a contemporaneidade, devido às inúmeras

40 Tradução livre do original em espanhol dos autores deste texto.

41 Para Rossi, as "esperanças sensatas” devem ser capazes de responder a três indagações: “[...] temos diante de nós razões de esperança? Há razões que podem nos poupar do desespero? Que fazem com que continuemos no caminho?". 
agressões às pessoas, ao meio ambiente, ao ordenamento social e às futuras gerações. A não reversão desse quadro constrangedor e caótico representará a abertura das condições para o colapso ambiental, humano e social.

A epistemologia do cuidado da "Casa Comum", exposta no decorrer do documento Laudato $S i$, representa uma alternativa política, social e ambiental para a construção de um modelo de convivência entre o Homem e a Natureza, o desenvolvimento e relações entre os povos pautada por referenciais que não reproduzam a atuação do Homem como centro desta rede de vida, especialmente nas ações de exploração, submissão e eliminação do Outro.

Essa tese, atualizada para o contexto da América Latina, demonstra a necessidade de efetivar um novo paradigma de relacionamento entre as pessoas e o meio ambiente, assim como de estabelecer objetivos e metas em vista da melhoria das condições de vida para todos no decorrer do tempo. Verifica-se, nesse momento, que a epistemologia da "Casa Comum" fornece as experiências e o esclarecimento necessário para desenvolver atitudes fundadas pelo cuidado, pela sustentabilidade, pela justiça e pela responsabilidade moral.

As gritantes desigualdades sociais, a instabilidade democrática e a expropriação dos recursos naturais e ambientais estão na origem dos altos índices de pobreza e escassez de recursos indispensáveis para a qualidade de vida. Os alicerces de uma "Casa Comum" não podem ser constituídos pela ignorância, miséria, opressão, submissão e eliminação, mas pelo esclarecimento e pela importância da diversidade vital que habita os ecossistemas neste continente.

O cuidado da "Casa Comum" ultrapassa fronteiras territoriais, círculos de interesses corporativos, grupos culturais, instituições e outros, para estabelecer condições e compromissos que visem a uma postura de preservação, admiração e utilização equilibrada dos recursos disponíveis. O seu discurso e práxis são, essencialmente, caracterizados por um fundamento ético e de justiça. Nesse cenário de dificuldades e ameaças, essa abordagem clama para a superação da indiferença e dos objetivos de curto prazo ou restritos aos Estados e a tolerância com ações, individuais ou coletivas, irresponsáveis em relação ao meio ambiente, às culturas e ao equilíbrio social.

A "Casa Comum" dos povos latino-americanos precisa tornar-se o local Viver Bem com responsabilidade. Os referenciais para essa nova relação precisam compreender, inicialmente, a necessidade de proteção e de 
valorização das tradições culturais, num prestar atenção constante aos seus valores, tradições e relações com a natureza, conforme ressalta Francisco, destacando especificamente as comunidades indígenas.

A continuidade desse projeto histórico comum contempla as demais tradições e formações culturais, as instituições, com suas diferentes metas e vocações, especificamente aquelas devotadas à pesquisa científica e acadêmica, à promoção humana e à assistência social, à educação e à saúde, ao desenvolvimento político e cultural, à organização do espaço urbano e das alternativas de produção ou convivência, entre outras. A unidade da vida - pressuposto basilar para fundar a "Casa Comum" - somente se torna possível a partir do reconhecimento e do cuidado de sua diversidade de seres interdependentes entre si.

Nessa configuração, orientada pelo cuidado da "Casa Comum", destaca-se a importância da negociação de acordos estruturados a partir de ampla participação social e não dependentes, exclusivamente, da atuação da diplomacia oficial, normalmente atrelada aos interesses corporativos do Estado Nacional.

Acordos, tratados e outros mecanismos que possam facilitar a integração e a proteção de pessoas, especialmente os imigrantes ou os perseguidos, e dos recursos naturais e ambientais, especificamente, as florestas, os rios, os lagos e os patrimônios culturais, são vitais para a qualidade de vida dos seres vivos e da casa de todos.

A arquitetura da "Casa Comum" é uma proposta alternativa de relacionamento entre Homem e Natureza, cuja responsabilidade de concretização é de todos, não obstante haja obstáculos para cumprir essa finalidade, como a precariedade de uma integração democrática e cultural existente na América Latina.

A palavra de Francisco, associada ao Princípio da Responsabilidade e à tradição latino-americana do bem viver, sedimenta e constitui referência universal atualizada para orientar e impulsionar ações de longo prazo e reconhecidas pela ampla maioria dos povos. Torna-se necessária uma nova configuração social que, ao longo do tempo, não se deixe cegar pelos interesses egoístas que encobrem a existência do Outro - seja humano ou não humano - e dificultam a vivência de uma comunhão universal. 


\section{REFERÊNCIAS}

BOFF, Leonardo. Ética da vida: a nova centralidade. Rio de Janeiro: Record, 2009.

BOFF, Leonardo. Saber cuidar: Ética do humano - compaixão pela terra. 19. ed. Petrópolis, (RJ): Vozes, 2013.

BOFF, Leonardo. Sustentabilidade: o que é: o que não é. Petrópolis, (RJ): Vozes, 2012.

BOSSELMANN, Klaus. O princípio da sustentabilidade: transformando direito e governança. Tradução de Phillip Gil França. São Paulo: Revista dos Tribunais, 2015.

FRANCISCO. Laudato si: sobre o cuidado da casa comum. São Paulo: Paulus/Loyola, 2015.

GIACOIA JÚNIOR, Osvaldo. Hans Jonas: o princípio da responsabilidade. In: OLIVEIRA, Manfredo Araújo de. Correntes fundamentais da ética contemporânea. 2. ed. Petrópolis, (RJ): Vozes, 2000.

GUARDINI, Romano. O fim da idade moderna: em procura de uma orientação. Tradução de M. S. Lourenço. Lisboa: Edições 70, 2000.

GUDYNAS, Eduardo. Cidadania ambiental e metacidadanias ecológicas: revisão e alternativas na América Latina. Desenvolvimento e Meio Ambiente, Curitiba, Universidade Federal do Paraná (UFPR), v. 19, dez. 2009. Disponível em: <http://ojs.c3sl.ufpr.br/ojs/index.php/made/article/ view/13954>. Acesso em: 3 mar. 2016.

HUANACUNI MAMANI, Fernando. Buen Vivir/Vivir Bien: filosofia, políticas, estratégias y experiências regionales andinas. Lima: CAOI, 2010.

KUJAWA, Henrique. Conflitos territoriais envolvendo indígenas e agricultores: uma análise histórica e jurídica de políticas públicas contraditórias. Curitiba: CRV, 2015. 
LÉVINAS, Emmanuel. Totalidade e infinito. Tradução de José Pinto Ribeiro. Lisboa: Edições 70, 2000.

MATTEI, Ugo. Bienes comunes: un manifiesto. Traducción de Gerardo Pisarello. Madrid: Trotta, 2013.

PASOLD, Cesar Luiz. A função social do Estado contemporâneo. 4. ed. Itajaí, (SC): Editora da Universidade do Vale do Itajaí - UNIVALI, 2013.

PASOLD, Cesar Luiz. Metodologia da Pesquisa Jurídica: teoria e prática. 13. ed. Florianópolis: Conceito, 2015.

REIS, Émilien Vilas Boas; BIZAWU, Kiwonghi. A encíclica Laudato Si à luz do direito internacional do meio ambiente. Revista Veredas do Direito, Belo Horizonte, v. 12, n. 23, Jan/jun. de 2015, p. 29-65. Disponível em: <http://www.domhelder.edu.br/revista/index.php/veredas/article/ view/598/439>. Acesso em: 12 mar. 2016.

ROSSI, Paolo. Esperanças. Tradução de Cristina Sarteschi. São Paulo: Editora da UNESP, 2013.

SARLET, Ingo Wolfgang. Dignidade da pessoa humana e direitos fundamentais na Constituição Federal de 1988. 9. ed. Porto Alegre: Livraria do Advogado, 2011.

STAFFEN, Márcio Ricardo. Interfaces do direito global. Rio de Janeiro: Lumen Juris, 2015.

UNASUL. União das Nações Sul-Americanas. Tratado constitutivo da UNASUL. Disponível <http://www.unasursg.org/index.php?option=com content\&view $=$ article\&id=290\&Itemid=339> . Acesso em: 12 mar. 2016.

ZAMBAM, Neuro José; AQUINO, Sérgio Ricardo Fernandes de. Tolerância: reflexões filosóficas, políticas e jurídicas para o século XXI. Revista da AJURIS. Porto Alegre, v. 142, n. 137, março de 2015. Disponível em: <http://www.ajuris.org.br/OJS2/index.php/REVAJURIS/article/ view/389/323 >. Acesso em: 22 fev. 2016. 
ZARKA, Yves Charles. O destino comum da humanidade e da Terra. Tradução de Anderson Vichikenski Teixeira. São Leopoldo, (RS): UNISINOS, 2014.

Artigo recebido em: 04/02/2017. Artigo aceito em: 11/08/2017.

\section{Como citar este artigo (ABNT):}

AQUINO, Sérgio Ricardo Fernandes de; ZAMBAM, Neuro José. A "Casa Comum": por uma epistemologia do cuidado e justiça para a América Latina. Veredas do Direito, Belo Horizonte, v. 14, n. 29, p. 101-123, maio/ ago. 2017. Disponível em: <http://www.domhelder.edu.br/revista/index. php/veredas/article/view/999>. Acesso em: dia mês. ano. 